\title{
Patterns of predation of Pink-footed Goose nests by polar bear
}

\author{
Jouke Prop ${ }^{1}$, Thomas Oudman², Tom M. van Spanje ${ }^{3} \&$ Eva H. Wolters ${ }^{4}$ \\ ${ }^{1}$ Arctic Centre, University of Groningen, P.O. Box 716, 9700 AS Groningen, the Netherlands; e-mail: jouke.prop@wxs.nl \\ ${ }^{2}$ NIOZ, P.O. Box 59, 1790 AB Den Burg, the Netherlands \\ ${ }^{3}$ Ripperdastraat 15 zwart, 2011 KG Haarlem, the Netherlands \\ ${ }^{4}$ Allersmaweg 56, 9891 TD Ezinge, the Netherlands
}

\begin{abstract}
This study explored patterns of predation by polar bear Ursus maritimus on the nests of Pink-footed Geese Anser brachyrhynchus on the coastal tundra stretch Nordenskiöldkysten, west coast of Spitsbergen, Svalbard. Goose nests occurred in densities of up to 126 nests $/ \mathrm{km}^{2}$ (mean=6.4), at an average distance of $1.5 \mathrm{~km}$ from the seashore, and were mainly associated with greenstone outcrops. Open, flat areas were avoided for nesting. Goose pairs nested in colonies of up to 23 nests, with 50\% of the pairs nesting in colonies larger than 5. In 2011 and 2012, polar bears invaded the Pink-footed Goose nesting area to consume goose eggs, a behaviour that they had not exhibited in previous years. Polar bears selectively visited the taller outcrops and locations with the larger number of goose nests. Moreover there was a steep gradient in predation from the seashore towards the inland, with no predation at distances greater than 1.8 $\mathrm{km}$ from the coastline. We expect that the predation pressure by polar bears will aggravate in the coming years when more bears learn to exploit the inland goose colonies.
\end{abstract}

Key words: Climate change, food selection, nest success, Svalbard

\section{INTRODUCTION}

Predation is among the key factors that shape an animal's life history (Newton 1998), and in the "battle of life" an animal's defence repertoire against predators is in a continuous process of refinement. However, an animal's skills to avoid predation may become futile when a new predator colonises its territory. In the extreme case, this may lead to local extinction of the prey species (Byström et al. 2007).

Arctic-breeding geese are an example of a group of birds that are a favoured prey for an array of predators. Gulls and skuas take eggs and small goslings, Arctic foxes Alopex lagopus depredate eggs, goslings and adults. Adaptations by the geese to avoid predation include nesting on predator-free places, and depositing body stores before onset of the breeding season to maximise the time to protect the clutch (Owen 1980, Black et al. 2007).

Recently, the polar bear Ursus maritimus has expanded its marine hunting habitat to the terrestrial environment (Rockwell \& Gormezano 2008, Smith et al. 2010). In Svalbard this has become evident by a larger number of polar bears spending the summer along the west coast of Svalbard than before (Drent \& Prop 2008), a process that may have been enhanced by recovery of the population after overharvest during much of the 20th century (Andersen et al. 2012). This change in behaviour has a large impact on, for example, Barnacle Geese Branta leucopsis breeding along the coasts of Svalbard. For successful hatching, the species depends on offshore islands which are inaccessible to Arctic foxes. However, these islands are an easy target for polar bears in search for food, leading to almost complete breeding failures (Drent \& Prop 2008, J.P. unpubl. data).

The Pink-footed Goose Anser brachyrhynchus lives in the same tundra areas as Barnacle Geese, and has escaped from bear predation due to the habit of generally nesting more inland than Barnacle Geese (Fox et al. 2009). However, from 2011 onwards we observed polar bears making forays into the interior tundra areas, visiting the characteristic breeding habitats of Pink-footed Geese. In this paper we explore the consequences for Pink-footed Geese of polar bears invading the terrestrial habitat of Svalbard. We do this by describing (1) the occurrence of Pink-footed Geese and its habitat choice on Nordenskiöldkysten, west coast of Svalbard; (2) the occurrence of polar bears in the area; and (3) goose nest success in relation to features of colony location. In doing so we show that it is precisely the stronghold of the goose breeding population that forms the prime target of polar bears. Finally, we discuss potential long-term consequences of polar bear predation for the Pink-footed Goose population in Svalbard. 


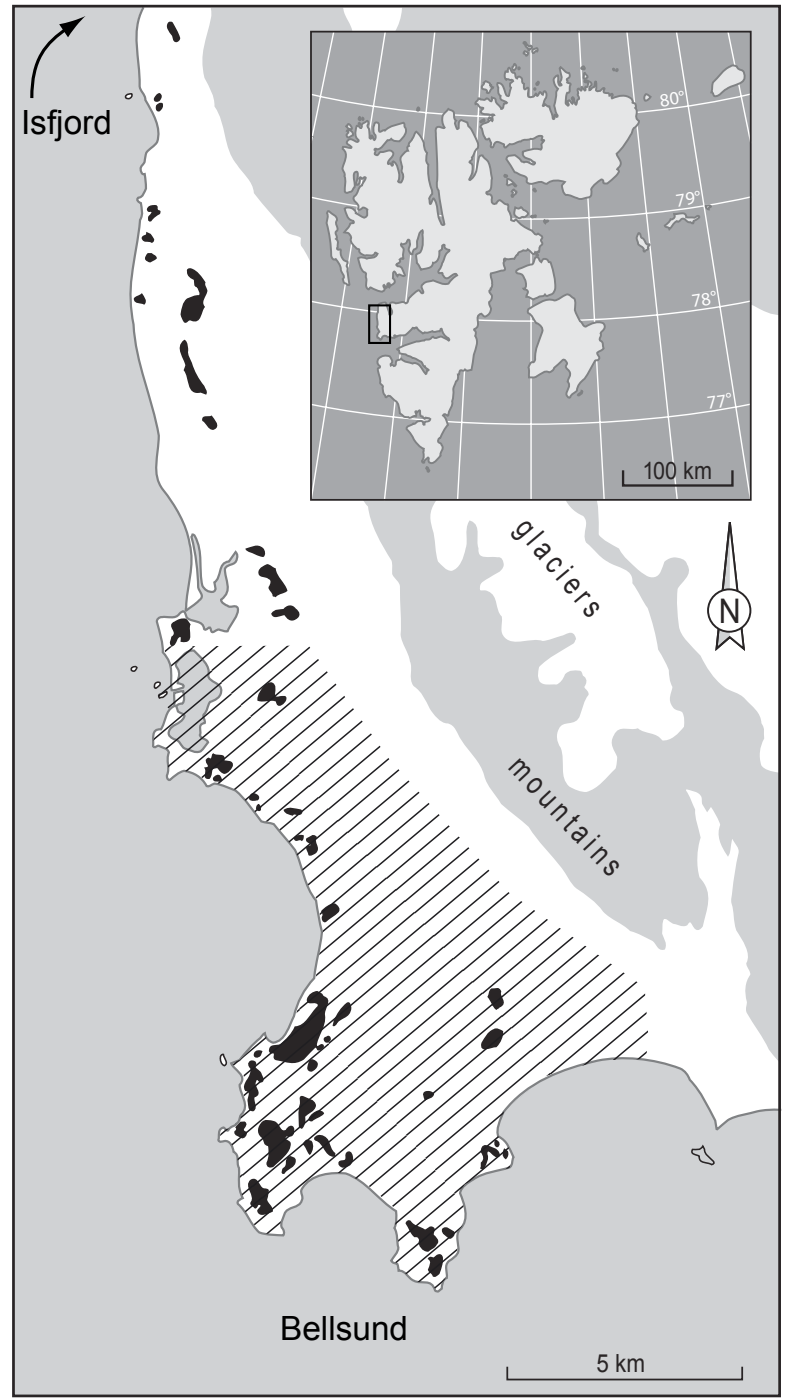

Figure 1. Location of Nordenskiöldkysten, west coast of Spitsbergen, Svalbard. Tundra lakes are in black. The core study area is indicated by hatching.

\section{METHODS}

Study area

Located on the west coast of Spitsbergen, Svalbard, Nordenskiöldkysten extends from the Isfjord in the north to Bellsund in the south (Figure 1). The core study area of $100 \mathrm{~km}^{2}$ is delineated by Gravsjøen $\left(77^{\circ} 52^{\prime} \mathrm{N}\right.$, $\left.13^{\circ} 41^{\prime} \mathrm{E}\right)$ in the north and Ytterdalselva and the $25-\mathrm{m}$ elevation line in the east. The geology of the area reflects a mixture of metamorphic late Precambrian bedrocks and more recent marine deposits (Hjelle et al. 1986). Mounds of up to $55 \mathrm{~m}$ elevation are found in the southern part of the coast, but generally the landscape is flat and is only broken by old inland raised beach ridges, running parallel to the present shore. Greenstone outcrops form remarkable landmarks on the tundra. Along the coast, greenstone islands are the home for breeding Barnacle Geese, Common Eiders Somateria mollissima and Glaucous Gulls Larus hyperboreus. Multiple lakes are found scattered along the coastline. Most of these lakes are fringed by vegetation composed of mosses, grasses and sedges. Together with the vast inland marshes, they provide an important feeding habitat for geese during the moult and brood-rearing period. Arctic foxes are a major predator of the geese and their eggs and are present throughout the area (Black et al. 2007).

\section{Goose surveys}

From 1977 onwards, Pink-footed Geese were counted during surveys in July-August, when all potential goose habitats were visited (as detailed in Drent \& Prop 2008). Numbers counted included breeding pairs (successful - with offspring -, and failed), nonbreeders, and goslings. Some of the non-breeders, present in the area during the incubation period, may have spent the moulting period along the east coast of Svalbard (Glahder et al. 2007). To assess to which extent the Nordenskiöldkysten population contributes to the total population, a comparison was made between the number of adults and goslings in the study area and the number counted in the wintering area as derived from published sources. To account for mortality between the summer and winter counts, the Nordenskiöldkysten numbers were corrected by survival estimates for the intervening period ( 0.50 for goslings as based on estimates from Barnacle Geese, Prop \& de Vries 1993, J.P. unpubl. data; 0.95 for adults based on Madsen et al. 2002). The number of juveniles and adults in the winter area was estimated as the product of the winter numbers and the estimated proportions of the two categories. Data for the wintering area (2000-2010) were derived from Madsen and Williams (2012) and Fred Cottaar (unpublished data).

In 2010-2012, the breeding distribution of Pinkfooted Geese was assessed by checking the study area systematically on foot. As the area was too large to cover in its entirety, some parts were surveyed in only one or two seasons. The survey took place after most of the eggs had hatched (from 10 July, 3 July, and 8 July onwards, in 2010, 2011, and 2012). Nests on outcrops and ridges were easier to spot from a distance than isolated nests on flat tundra. We cannot, therefore exclude the possibility that the number of isolated nests in the flat tundra was underestimated. Large-scale inventories earlier in the summer aimed at detecting other breeding species indicated however that the number of pink-footed nests that we missed during the surveys must have been small. Nests were scored as 'successful' (the nest scrape containing eggshell fragments and membranes separated from the shells; Mabee 1997) or 'failed' (no eggshells, eggshells with 

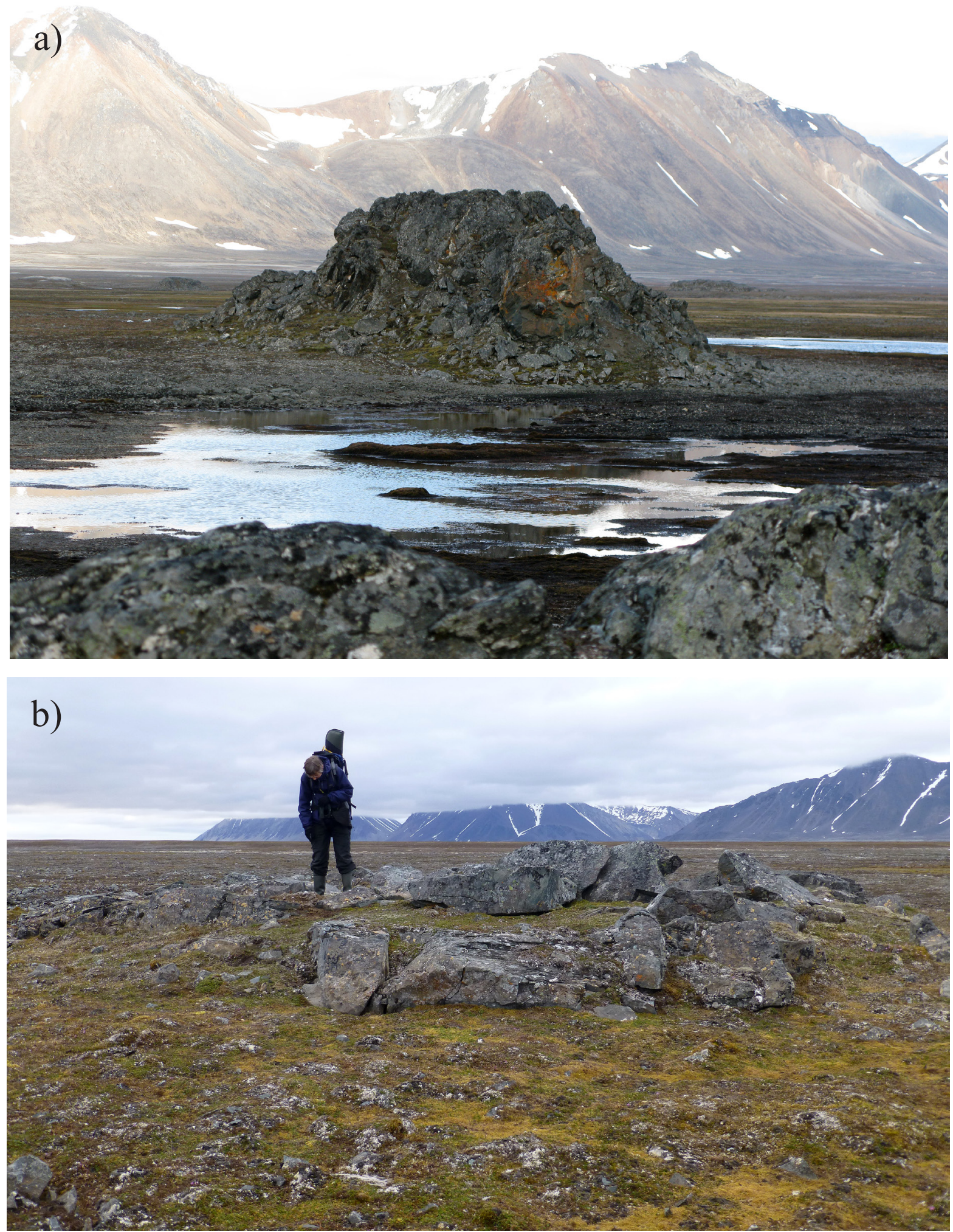

Figure 2. Examples of nesting habitats of Pink-footed Geese on Nordenkiöldkysten: a) rock and b) ridge.

clear signs of punctures or bites by gulls or foxes, or eggshells in a compact ball after being chewed by polar bears). Successful and failed nests had fresh droppings on the nest rim and in the immediate vicinity. Nests without fresh droppings or down were recorded as 'unused'. The nest positions were recorded by a handheld GPS.

Based on the geographical positions of the Pinkfooted Goose nests, a matrix was generated containing distances among all nests. From this matrix, nests 
were aggregated into 'colonies' such that each nest in a colony was closer than $25 \mathrm{~m}$ to at least one other nest. Nests that had a distance of more than $25 \mathrm{~m}$ to the nearest neighbour formed a 'colony' of size 1. A cut-off distance of $25 \mathrm{~m}$ was chosen based on field assessments: colonies distinguished this way corresponded well to aggregates associated with individual rocks or ridges. To establish colony identity over the years, colony locations in different years were compared and matched.

The following parameters were recorded for each of the colonies (Figure 2):

(1) Habitat type. Rocks: discrete rock formations emerging from the tundra, having a steep slope on at least one side. Rocks were usually composed of solid greenstone, and in some cases of calcareous rocks. Ridges: slightly elevated rims that gradually emerged from the surrounding tundra. Goose nests were usually located between greenstone or limestone rocks. Flat tundra: on dry, raised beach ridges, or in wet moss marshes. Shelter for the nest was usually limited to a slight elevation in the terrain.

(2) Height: visually estimated as the vertical size of the rock or ridge.

(3) Distance to the seashore: derived from an electronic topographical map (Topo Explorer Svalbard of GeoInsight and Norwegian Polar Institute) with the colony locations plotted using Garmin MapSource 6.16 .

Nest success was calculated as the proportion of successful nests to the total number of nests in a colony.

To assess breeding densities, the study area was subdivided in 1-square-km blocks corresponding to the UTM grid. Colony locations were assigned to the appropriate squares and for each location the maximum number of occupied nests over 2010-2012 was determined. These colony sizes were summed to give the number of nests per square.

\section{Polar bears}

Polar bears observed by us probably originated from the adjacent Bellsund-Van MijenfjordenVan Keulenfjorden complex that is known to host a small population of Polar Bears throughout the year (Lydersen et al. 2002). We collected observations opportunistically. As soon as a bear came in view we recorded its location using various features in the landscape that were visible on aerial photographs of the area. This enabled us to determine how much of the time was spent at a particular distance from the seashore. Records of individual bears were expressed in bear days, i.e. the number of dates that an individual was seen in the study area. Summed over all individuals this gave a measure for the seasonal abundance. For the purpose of this paper, observations are restricted to the goose incubation period (25 May-15 July).

\section{Statistical tests}

Nest success of Pink-footed Geese was modelled by Generalized Linear Mixed Models (GLMM) adopting a binomial distribution with a logit link function ( successful $=1$, failed $=0$ ) in program R 2.15.1 ( $\mathrm{R}$ Development Core Team 2012) using package lme4. Colony location was included as a random effect to account for repeated sampling of the same locations. Colony size (number of occupied nests in the colony), height of the colony location, distance of the colony to the seashore, and year were fixed effects. Modelling started with all relevant terms in the model, and subsequently terms were dropped when they did not contribute significantly to the model based on a likelihood ratio test (comparing models with and without the term by anova in R). Predictions and associated confidence intervals were calculated following Bolker (2008). If not otherwise stated, means are reported \pm SD.

\section{RESULTS}

\section{Occurrence of Pink-footed Goose}

The sparse complete counts of Pink-footed Geese during the moulting period indicated an initial stable population of approximately 350 individuals. From 1999 onwards numbers increased rapidly by $9.4 \%$ per year (Figure 3), with at present 1000-1400 adults staying in the area in summer. The northern part of the coastline, which was less frequently surveyed, added on average 375 (range 220-550) adult geese to this number. Nordenskiöldkysten produced on average

Table 1. Features of pink-footed goose colonies by nest location type. Given are means \pm SD of height of the colony location (relative to the surrounding area), distance of the colony to the seashore, colony size, and nearest neighbour distance NND within the colony. Range is given between brackets. Superscript letters indicate significant differences by Tukey HSD test in a column-wise comparison.

\begin{tabular}{lccccl}
\hline Nest location & $\mathrm{n}$ & Height $(\mathrm{m})$ & Distance to shore $(\mathrm{km})$ & Colony size, $\mathrm{n}$ nests & NND $(\mathrm{m})$ \\
\hline Flat tundra & 35 & $0.00 \pm 0.00^{\mathrm{a}}$ & $1.73 \pm 0.90$ & $1.00 \pm 0.00^{\mathrm{a}}(1-1)$ & - \\
Ridge & 43 & $0.76 \pm 0.25^{\mathrm{a}}$ & $1.54 \pm 0.45$ & $1.39 \pm 0.73^{\mathrm{a}}(1-5)$ & $13.30 \pm 8.04^{\mathrm{a}}(\mathrm{n}=14)$ \\
Rock & 136 & $2.39 \pm 1.44^{\mathrm{b}}$ & $1.37 \pm 0.60$ & $3.55 \pm 4.21(1-23)$ & $9.29 \pm 6.33^{\mathrm{b}} \quad(\mathrm{n}=85)$ \\
\hline
\end{tabular}




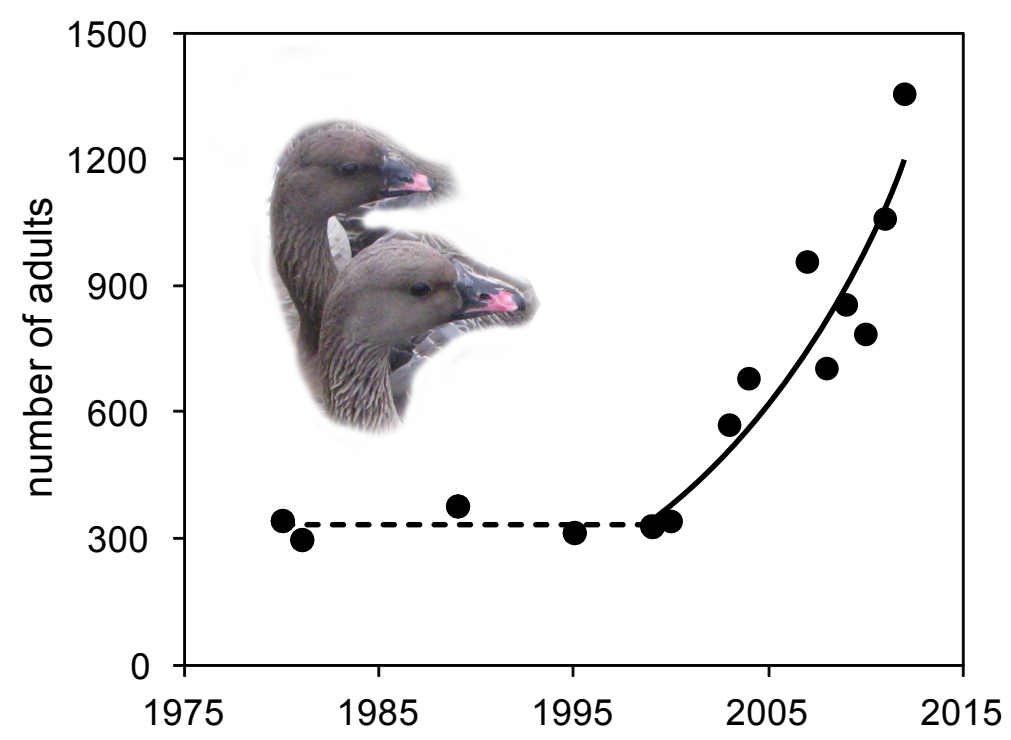

Figure 3. Local population size of Pink-footed Geese on Nordenskiöldkysten, Svalbard, in 1977-2012. Figures refer to the number of adult geese in the area southwards from Gravsjøen during the moulting and brood-rearing period. The regression line follows from an exponential growth model $\left(\mathrm{y}=\mathrm{e}^{(0.094 \times \text { Year }+5.86)}, \mathrm{R}^{2}=0.88\right.$, period 1999-2012).

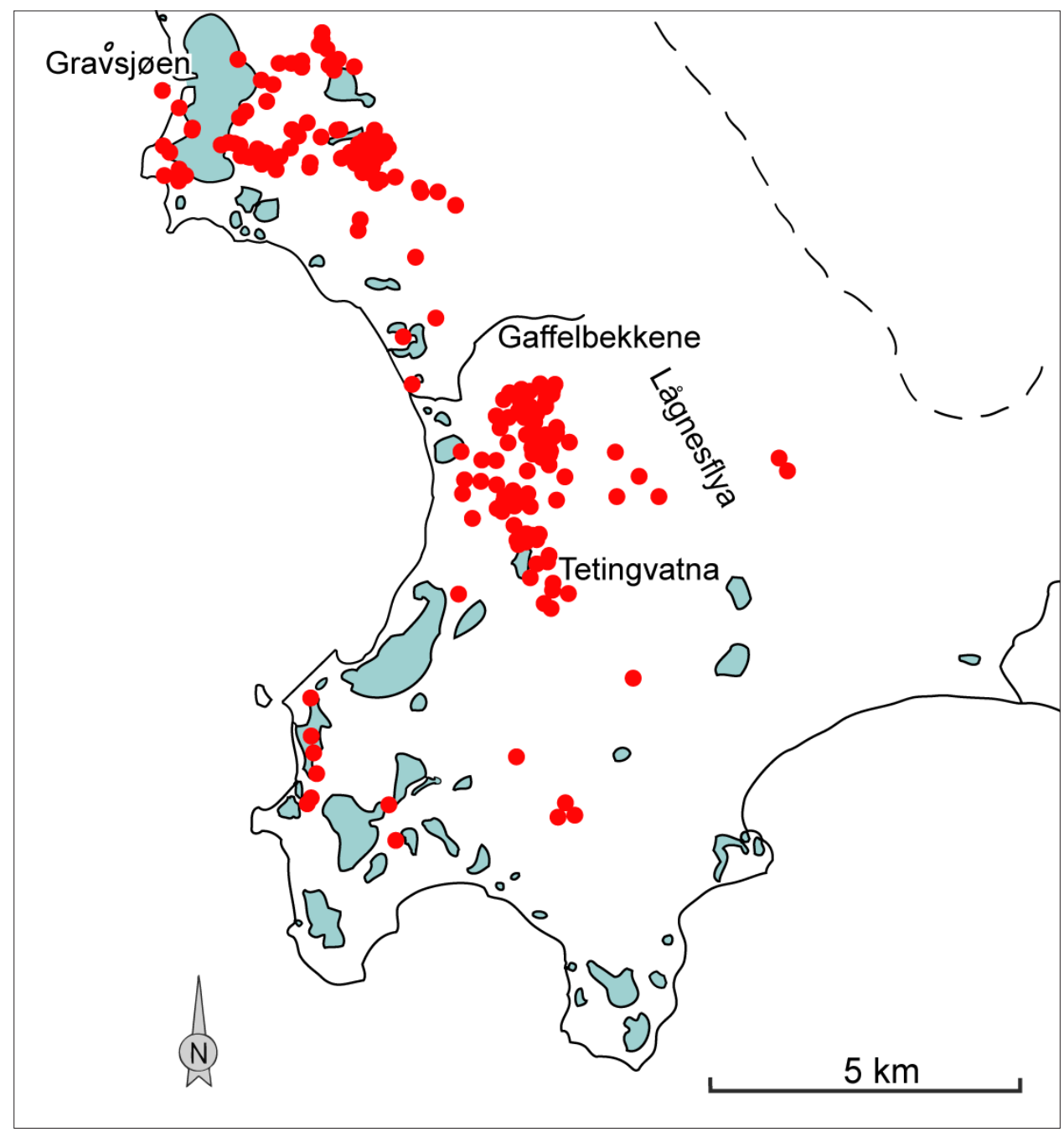

Figure 4. Distribution of Pink-footed Goose colonies in the study area on Nordenskiöldkysten, Svalbard. Each dot represents a single colony, composed of 1-23 nests. 
Table 2. Probability of a polar bear visit to Pink-footed Goose colonies in relation to colony height, distance to seashore, colony size, year, and relevant interaction terms. Given are the results of a GLMM: estimates and SE with associated test statistics of the final model. Colony location was a random factor. Interaction terms year $\times$ height $\left(\chi^{2}=0.40\right)$ and year $\times$ distance $\left(\chi^{2}=3.69\right)$ did not qualify for inclusion in the model. Data are from 2011 and 2012.

\begin{tabular}{|c|c|c|c|c|}
\hline & Estimate & $\mathrm{SE}$ & $\mathrm{Z}$ & $\mathrm{p}$ \\
\hline Intercept & -0.801 & 0.682 & -1.17 & 0.24 \\
\hline Height & 0.456 & 0.187 & 2.44 & 0.015 \\
\hline Distance & -0.0021 & 0.0005 & -4.51 & $<0.001$ \\
\hline Colony size & 0.133 & 0.060 & 2.23 & 0.026 \\
\hline Year 2011 & 0.0 & & & \\
\hline Year 2012 & -1.069 & 0.511 & -2.09 & 0.036 \\
\hline
\end{tabular}

$3.0 \%$ (range $1.3-6.3 \%$ ) of the goslings as counted in the autumn flocks, whereas the adults comprised $2.0 \%$ (range 1.6-2.5\%) of the total Svalbard population. This indicates that the area produced $50 \%$ more goslings than expected on the basis of number of adults.

Whereas Pink-footed Geese nested across the whole gradient from close to the seashore to the terraces lining the inland mountains (Figure 4), most of the nests were located several km's from the coast. The modal distance of nests from the shore was $1.7 \mathrm{~km}$. Goose nesting was very local, with $4 \%$ of the $1-\mathrm{km}$ squares (n $=100$ ) containing over $50 \%$ of all nests, and $62 \%$ of the squares containing no nest at all. The average density was 6.4 nests $/ \mathrm{km}^{2}$ (range $0-126$ nests $/ \mathrm{km}^{2}$ ). Two fields in particular attracted large numbers of breeding geese: one $\left(6 \mathrm{~km}^{2}\right)$ around Gravsjøen, the other $\left(4 \mathrm{~km}^{2}\right)$ in the Gaffelbekkene-Tetingvatna area (Figure 4). Together these fields contained $95 \%(n=641)$ of all nest sites. Comparing our data with a geological map of the area (Hjelle et al. 1986) reveals a striking resemblance between the distribution of Pink-footed Goose nests and the occurrence of Late Precambrian metamorphic stones with greenstone outcrops. In contrast, flat marshes on marine sediments, covering $50 \%$ of the study area and containing $1.2 \%$ of the nests, were apparently avoided for nesting.

The apparent preference of Pink-footed Geese for greenstone outcrops is also evident when considering the habitats where colonies were located. Most of the colonies were on rocks $(63.6 \%$, Table 1$)$, followed by ridges $(20.0 \%)$ and flat tundra $(16.4 \%)$. The largest rocky outcrops were $7 \mathrm{~m}$ high and had a length of up to $130 \mathrm{~m}$. These rocks contained up to 23 occupied nests, but smaller outcrops contained fewer nests (on average 3.54). Ridges were on average less than $1 \mathrm{~m}$ high (Table 1), and the number of nests per colony was smaller than on rocks (Table 1). On flat tundra only single nests were found, with no other nests in the immediate surroundings.

\section{Occurrence of polar bear}

During the summer months polar bears used to be rare in the study area with less than two observations per year. However, in the early 2000s bear numbers exhibited a striking increase. In 2004-2012 we recorded a total of 117 bear days, with on average 8 different individuals within each of the seasons. The number of bear days during the goose incubation period centred around 10 days per 30 observation days.

The majority of the bears stayed close to the coastline, spending only $5.3 \%$ of the time at a distance more than $1 \mathrm{~km}$ from the shore ( $>500$ observation hours). In 2011 we observed - for the first time - that polar bears had conducted forays in the nesting area of Pink-footed Geese. In the following year, polar bears repeated their visits to the Pink-footed Goose nesting area. We established predation in the colonies based on direct observations $(n=9)$, or we inferred predation from a combination of (1) presence of bear

Table 3. Pink-footed Goose nest success in relation to colony height, distance to seashore, colony size, year, and relevant interaction terms. Given are the results of a GLMM: estimates and SE with associated test statistics of the final model. Colony size $\left(\chi^{2}=0.74\right)$ did not qualify for inclusion in the model. Colony location was a random factor.

\begin{tabular}{lclcc}
\hline & Estimate & SE & $\mathrm{z}$ & $\mathrm{p}$ \\
\hline Intercept & 1.079 & 0.787 & 1.37 & 0.17 \\
Height & 0.095 & 0.0999 & 0.95 & 0.34 \\
Distance & -0.0007 & 0.0005 & -1.43 & 0.15 \\
Year 2010 & 0.000 & & & \\
Year 2011 & -1.113 & 0.9125 & -1.22 & 0.22 \\
Year 2012 & -1.869 & 0.844 & -2.21 & 0.03 \\
Height $\times$ year 2011 & -0.535 & 0.1211 & -4.42 & $<0.001$ \\
Height $\times$ year 2012 & -0.371 & 0.1051 & -3.53 & $<0.001$ \\
Distance $\times$ year 2011 & 0.0017 & 0.0006 & 3.08 & 0.002 \\
Distance $\times$ year 2012 & 0.0012 & 0.0005 & 2.35 & 0.019 \\
\hline
\end{tabular}



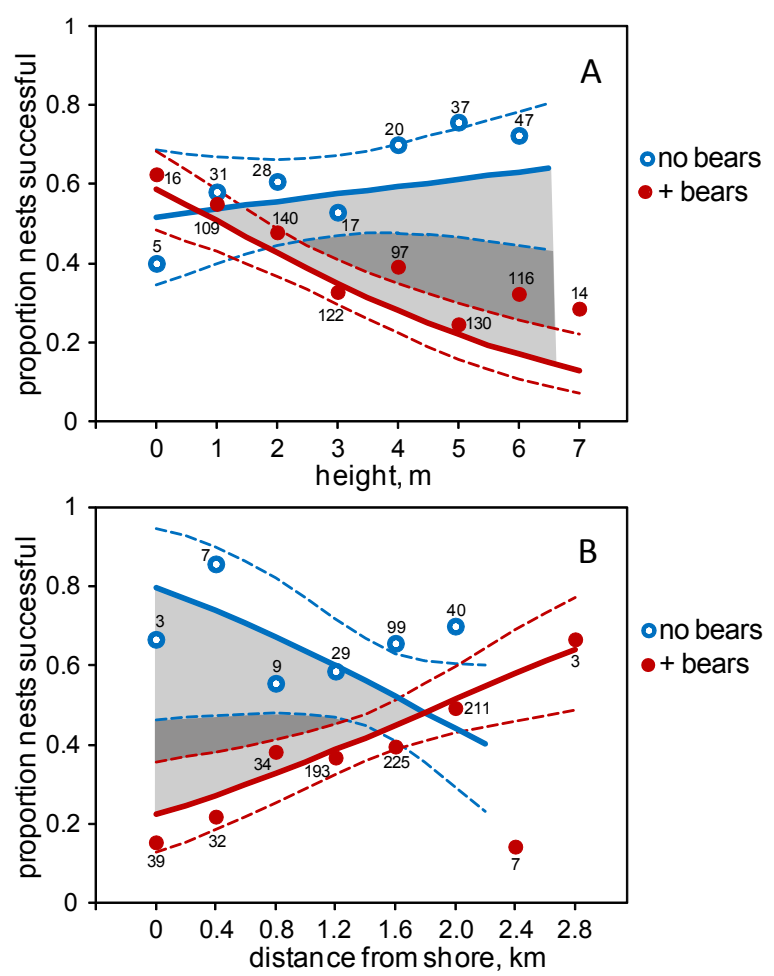

Figure 5. Pink-footed Goose nest success in relation to (A) height of the colony location, and (B) distance of the colony to the seashore. Given are means with associated sample sizes for years without bears in the colonies (2010) and with bears present (2011 and 2012). For clarity of presentation, regression lines with $95 \%$ confidence intervals are based on a simplified model of Table 1 (two year classes rather than three years). The decrement in success in bear years is indicated by shading (light grey delineated by the regression lines, dark grey beyond the confidence intervals).

scat, (2) foot prints in mud or snow, (3) remains of eggshells indicating bear predation $(n=22)$. To check how effective we were in detecting bears as source of breeding failure, we visited the nine colonies where we observed predation by bears. In only six of these colonies we found evidence of bear predation. This indicates that we missed predation events if not directly observed, and that we must have underestimated the number of colonies visited by polar bears. When bears visited a colony, not all nests were predated. On average $14.3 \%( \pm 22.3, \mathrm{n}=31$ colonies $)$ of the nests escaped predation.

The probability of a polar bear visiting a colony was positively affected by colony height and colony size, and negatively by the distance to the seashore (Table 2). Moreover there was a year effect, with a larger probability of predation in 2011 than in 2012.

\section{Nest success of Pink-footed Goose}

The nest success of Pink-footed Geese differed widely among years $(66.6 \%, 55.0 \%$, and $31.1 \%$ in 2010,2011 and 2012; GLM Wald $=78.2$, df $=2, \mathrm{P}<0.0005$ ). Moreover, nest success varied with colony height and distance to the sea (Table 3). Significant interaction terms indicated that the effects of height and distance differed among years. In 2010 nest success was positively related to height (non-significant), whereas in the following two years nest success showed a strong negative relationship with height. Distance to the sea exhibited a similar trend, though in the opposite direction; in 2011 and 2012, nest success was positively related to the distance to sea. We attribute the shift in trends, which coincided with the appearance of polar bears, to the immediate effects of bear predation. The 95\% confidence intervals of the regressions (Figure 5) indicate a drop in nest success during the polar bear years (1) in colonies on rocks higher than $2 \mathrm{~m}$, and (2) in colonies closer than $1.25 \mathrm{~km}$ from the seashore.

\section{DISCUSSION}

Nordenskiöldkysten hosted a considerable portion of the Svalbard Pink-footed Goose population. Moreover, more offspring was produced than expected on the basis of the number of adults. One of the reasons for the high quality of the area is the presence of suitable nesting places, which can be defended against Arctic Foxes (Owen 1980), combined with vast marshes (Holmungen and Lågnesflya) that provide suitable habitat for moulting and rearing young. During the years of this study, Pink-footed Goose reproductive success came under pressure by the invasion of polar bears. Effects of bear depredations were strong because bears exhibited a preference for goose colonies on high rock formations, which contained a large number of nests, exactly the stronghold for the breeding population in this area of Svalbard. Added to this, the larger size and potentially better prospects for a successful hatch (Karagicheva et al. 2011) leads us to suspect that larger colonies were inhabited by competitive individuals giving better chances of survival to their offspring (Prop et al. 1984, Stahl et al. 2001). As a consequence, bear predation was stronger than one could expect on the basis of the number of colonies visited by bears alone.

Polar bears started to exploit Pink-footed Goose colonies in 2011, a behaviour that we had not witnessed in any previous year in the study area. Instead, bears had been heavily exploiting Barnacle Goose and Eider colonies on offshore islands from the early 2000s onwards (Drent \& Prop 2008). Similarly, Madsen et al. (1998) described polar bear predation in Light-bellied Brent Goose colonies on small islands in southeast Svalbard. We speculate that the bears had developed a 'searching image' for the breeding locations of Pinkfooted Geese, possibly somewhere else along the west 
coast of Svalbard where Pink-footed Geese nest close to the shore, employing their new skills in our area. An argument in favour of this hypothesis is that the number of bears involved in searching for Pink-footed Goose nests was small (3 individuals in 2011, 5 in 2012; total number of individuals in the area 10 and 8, respectively). Evidence that the bears had learned the 'trick' elsewhere comes from the observation that one of the bears feeding on Pink-footed Goose eggs in our area had been observed (and photographed) from a cruise boat ( $\mathrm{S} / \mathrm{V}$ 'Anne Margaretha') earlier in the season on the opposite side of the Bellsund feeding on Pink-footed Goose nests located close to the shore.

Successful reproduction of geese depends on a timely disappearance of snow from the tundra (Prop \& de Vries 1993, Madsen et al. 2007). Therefore, the observed differences among years in Pink-footed Goose nest success may have been due to differential rates of snowmelt. The date that $50 \%$ of the tundra becomes snow-free is a critical yardstick during the incubation period of geese (Prop \& de Vries 1993). In 2011 and 2012 snow melt was later than in 2010, and conditions for breeding may have been less favourable (50\% of snow clearance of the coastline was on 1,14 and 8 June in 2010-2012). It is therefore possible that nests that were predated by polar bears in 2011 and 2012 would have been abandoned by the geese anyway. On the other hand, it is unlikely that the relationships between nest success and features of the nest location in the years with bear predation (a negative association with height of colony, and a positive association with distance to the seashore, Figure 5) has been generated by less favourable snow conditions. If snow were to affect these relationships, we would expect opposite trends: relatively favourable conditions on the highest rocks (where wind causes large snow-free patches) and close to the seashore (where conditions are milder than inland).

It is possible that the bears' interest in goose eggs stems from deteriorating foraging conditions in the main bear hunting habitat, sea ice, which makes their main prey (seals) inaccessible. Rockwell and Gormezano (2008) suggested that at the west coast of the Hudson Bay, Canada, Lesser Snow Goose Anser caerulescens eggs might become a non-trivial contribution to the polar bear's energy needs when sea ice cover diminishes at a similar rate as in the past years, and egg consumption might mitigate adverse effects of changing ice conditions. However, Pink-footed Goose nests on Svalbard do not seem an alternative for seals as the total number of Pink-footed Geese is small compared to North-American goose populations (less than 80000 for the whole archipelago versus 100000s of Snow Geese for the western Hudson Bay; Madsen \& Williams 2012 and Alisauskas et al. 2012, respectively). Although the Pink-footed Goose population has shown a remarkable increase during the past decade, scope for further growth in numbers seems limited now that concern for human welfare urges for population control (Madsen \& Williams 2012).

Despite extensive bear forays on the tundra, many of the goose nests escaped predation. There were two main reasons why the predation pressure was limited. First, not all nests in a colony were predated. This was surprising as bears seemed to have little problems in detecting colonies (Prop 2012). We speculate that polar bears have learned to use clearly visible cues (at least to the human eye) to locate a breeding colony, i.e. rocky outcrops. However, they may not be able to estimate the number of nests present in the colony, or they do not use their senses (smell in particular) to locate individual nests. This is in agreements with observations in Barnacle Goose colonies, which showed that polar bears stop foraging as soon as searching time for nests increases, even when many more nests are available in the colony (J. Prop, unpublished data). Nevertheless, predation rates in Barnacle Goose colonies are extremely high (up to $100 \%$ of the nests predated), but this is due to the accumulated effects of successive bears visiting the breeding colonies.

Secondly, predation pressure was limited as polar bear predation exhibited a strong spatial gradient, and there was a decreasing probability for bears to visit a colony at a larger distance from the seashore. No predation was observed at a distance greater than $1.8 \mathrm{~km}$ from the coast, whereas $30 \%(\mathrm{n}=214)$ of the colonies were located beyond this distance. It remains to be seen how bear behaviour evolves over time, and whether bears will extend their search effort to exploit colonies further inland as well. As yet, there seems no reason why bears would not move further from the coast as we observed bears far inland later in the season (after geese had hatched), in accordance with records elsewhere (Stirling 2011).

At this stage, any predictions on the future impact of polar bears on Pink-footed Geese are bound to be uncertain. A large portion of the goose population breeds within several $\mathrm{km}$ from the sea or fjord coast (Mehlum 1998), and nests are potentially within reach of polar bears. The strength of predation will depend on changes in food availability for polar bears and to what extent bears are pushed to exploit food resources other than seals. The number of bears residing on Svalbard, and changes therein, will play a crucial role. In the years to come, it is expected that the breeding conditions of Pink-footed Geese in Nordenskiöldkysten will deteriorate as more bears learn how to exploit and detect the Pink-footed Goose colonies, and bears extend their foraging range by moving further inland.

Acknowledgements. Many thanks to Sieds Boersma, Oebele Dijk, Arjen Drost, Larry Griffin, Brian Morrell, Annette Scheepstra, and Ronald Visser for help during the field work, and to the Office of the Governor of Svalbard, 
Christiane Hübner, and Maarten Loonen for logistical support. The paper improved a lot by the input from Helen Brenda Anderson and Paul Shimmings. Rudi Drent is gratefully remembered for stimulating research in the Arctic.

\section{REFERENCES}

Alisauskas, R.T., Leafloor, J.O. \& Kellett, D.K. 2012. Population status of Midcontinent Lesser Snow Geese and Ross's Geese following special conservation measures. Pp. 132-177 in: Leafloor, J.O., Moser, T.J. \& Batt, B.D.J. (eds.). Evaluation of special management measures for midcontinent lesser snow geese and Ross's geese. AGJV Special Publication. USFWS, Washington, D.C. and CWS, Ottawa, Ontario.

Andersen, M., Derocher, A.E., Wiig, Ø. \& Aars, J. 2012. Polar bear (Ursus maritimus) maternity den distribution in Svalbard, Norway. Polar Biology 35: 499-508.

Black, J.M., Prop, J. \& Larsson, K. 2007. Wild goose dilemmas: population consequences of individual decisions in Barnacle Geese. Branta Press, Groningen.

Bolker, B.M. 2008. Ecological models and data in R. Princeton University Press, Princeton.

Byström, P., Karlsson, J., Nilsson, P., Van Kooten, T., Ask, J. \& Olofsson, F. 2007. Substitution of top predators: effects of pike invasion in a subarctic lake. Freshwater Biology 52: 1271-1280.

Drent, R.H. \& Prop, J. 2008. Barnacle goose Branta leucopsis survey on Nordenskiöldkysten, west Spitsbergen 19752007: breeding in relation to carrying capacity and predator impact. Circumpolar Studies 4: 59-83.

Fox, A.D., Eide, N.E., Bergersen, E. \& Madsen, J. 2009. Resource partitioning in sympatric arctic-breeding geese: summer habitat use, spatial and dietary overlap of Barnacle and Pink-footed Geese in Svalbard. Ibis 151: 122-133.

Glahder, C.M., Fox, A.D., O’Connell, M., Jespersen, M. \& Madsen, J. 2007. Eastward moult migration of nonbreeding Pink-footed Geese (Anser brachyrhynchus) in Svalbard. Polar Research 26: 31-36.

Hjelle A., Lauritzen, Ø., Salvigsen, O. \& Winsnes, T.S. 1986. Geological map of Svalbard, 1:100,000, Sheet B10G Van Mijenfjorden. Norsk Polarinstitutt, Oslo.

Karagicheva, J., Rakhimberdiev, E., Dobrynin, D., Saveliev, A., Rozenfeld, S., Pokrovskaya, O., Stahl, J., Prop, J. \& Litvin, K. 2011. Individual inter-annual nest-site relocation behaviour drives dynamics of a recently established Barnacle Goose Branta leucopsis colony in sub-arctic Russia. Ibis 153: 622-626.

Lydersen, C., Krafft, B.A., Andersen, M. \& Kovacs, K.M. 2002. Marine mammals in the Bellsund-Van MijenfjordenVan Keulenfjorden area. Norsk Polarinstitutt Rapport 121: $1-36$.

Mabee, T.J. 1997. Using eggshell evidence to determine nest fate of shorebirds. Wilson Bulletin 109: 307-313.
Madsen, J., Bregnballe, T., Frikke, J. \& Kristensen, J.B. 1998. Correlates of predator abundance with snow and ice conditions and their role in determining timing of nesting and breeding success in Svalbard Light-bellied Brent Geese Branta bernicla hrota. Norsk Polarinstitutt Skrifter 200: 221-234.

Madsen, J., Frederiksen, M. \& Ganter, B. 2002. Trends in annual and seasonal survival of Pink-footed Geese Anser brachyrhynchus. Ibis 144: 218-226.

Madsen, J., Tamstorf, M., Klaassen, M., Eide, N., Glahder, C., Riget, F., Nyegaard, H. \& Cottaar, F. 2007. Effects of snow cover on the timing and success of reproduction in high-Arctic Pink-footed Geese Anser brachyrhynchus. Polar Biology 30: 1363-1372.

Madsen, J. \& Williams, J.H. 2012. International species management plan for the Svalbard population of the Pinkfooted Goose Anser brachyrhynchus. AEWA Technical Series No. 20, Bonn.

Mehlum, F. 1998. Areas in Svalbard important for geese during the pre-breeding, breeding and post-breeding periods. Norsk Polarinstitutt Skrifter 200: 41-55.

Newton, I. 1998. Population limitation in birds. Academic Press, London.

Owen, M. 1980. Wild geese of the world. Batsford Ltd, London.

Prop, J. 2012. Polar bears detect Pink-footed Goose nests and consume the eggs. http://www.youtube.com/joukeprop

Prop, J., van Eerden, M.R. \& Drent, R.H. 1984. Reproductive success of the Barnacle Goose Branta leucopsis in relation to food exploitation on the breeding grounds, western Spitsbergen. Norsk Polarinstitutt Skrifter 181: $87-118$.

Prop, J. \& de Vries, J. 1993. Impact of snow and food conditions on the reproductive performance of Barnacle Geese Branta leucopsis. Ornis Scandinavica 24: 110-121.

R Development Core Team 2012. R: A language and environment for statistical computing. R Foundation for Statistical Computing, Vienna.

Rockwell, R.F. \& Gormezano, L.J. 2009. The early bear gets the goose: climate change, polar bears and Lesser Snow Geese in western Hudson Bay. Polar Biology 32: 539-547.

Smith, P.A., Elliott, K.H., Gaston, A.J. \& Gilchrist, H.G. 2010. Has early ice clearance increased predation on breeding birds by polar bears? Polar Biology 33: 1149-1153.

Stahl, J., Tolsma, P.H., Loonen M.J.J.E. \& Drent, R.H. 2001. Subordinates explore but dominants profit: Resource competition in high Arctic Barnacle Goose flocks. Animal Behaviour 61: 257-264.

Stirling I. 2011. Polar bears: the natural history of a threatened species. Fitzhenry \& Whiteside, Markham, Canada.

Received 09 October 2012. Accepted 14 June 2013 Guest editor: Paul Shimmings 